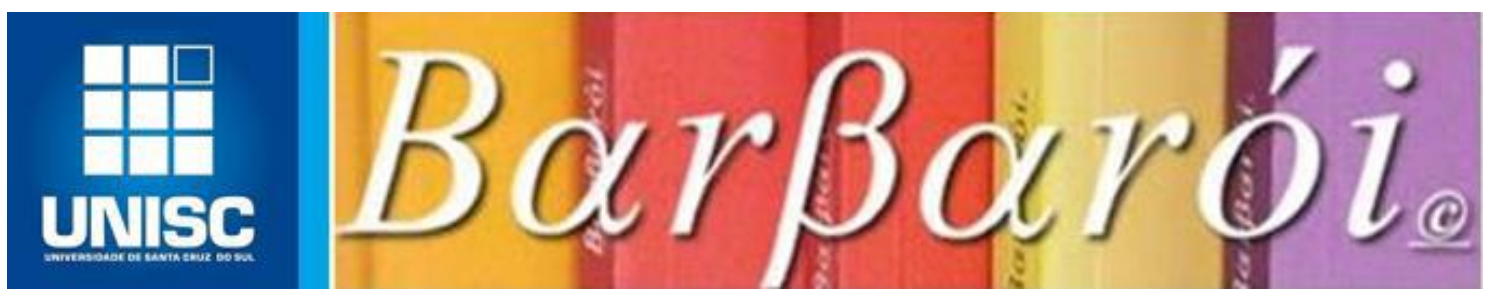

\title{
IMPLEMENTAÇÃO DO PROGRAMA MINHA CASA MINHA VIDA EM SANTA CRUZ DO SUL: A PERCEPÇÃO DOS BENEFICIÁRIOS ${ }^{1}$
}

\author{
DOI: http://dx.doi.org/10.17058/barbaroi.v0i0.14597 \\ $*$ \\ Claudia Tirelli \\ Universidade de Santa Cruz do Sul - UNISC - Brasil \\ Sílvia Virgínia Coutinho Areosa \\ Universidade de Santa Cruz do Sul - UNISC - Brasil
}

\section{Resumo}

$\mathrm{O}$ artigo discute os resultados de uma pesquisa avaliativa desenvolvida com moradores de dois conjuntos habitacionais construídos em Santa Cruz do Sul/RS, por meio do Programa Minha Casa Minha Vida (PMCMV). A partir da realização de um survey e de observações diretas nos residenciais, buscou-se analisar como os beneficiários do Programa percebem os efeitos da sua implementação, a qual resultou no seu deslocamento no espaço urbano e alterações nas suas redes de sociabilidade, condições de moradia e acesso a serviços e equipamentos públicos. Com base nesses dados, pôde-se apreender a "efetividade subjetiva" do Programa, a qual difere das avaliações que buscam aferir se as metas e objetivos previstos na fase da formulação da política foram alcançadas. $\mathrm{O}$ estudo apontou que a implementação do PMCMV propiciou a aquisição da "casa própria", mas trouxe diversos efeitos colaterais para os seus beneficiários, a depender da localização do conjunto habitacional no espaço urbano e da tipologia utilizada na construção das unidades residenciais (casas ou prédios; conjuntos murados ou abertos) e das suas formas de gestão. Entre esses efeitos não esperados pode-se apontar o recrudescimento da violência vinculada ao tráfico de drogas, dificuldades de estabelecer regramentos e novos laços no convívio social, a distância e precariedade dos serviços públicos e o endividamento, abandono e ocupação das residências.

Palavras chave: Programa Minha Casa Minha Vida, política pública, implementação.

\footnotetext{
${ }^{1}$ Este artigo é uma versão modificada de um trabalho apresentado no XVIII ENANPUR ocorrido em Natal, maio de 2019.
} 


\section{Introdução}

Na última década, diversos estudos desenvolvidos no Brasil demonstraram que houve uma melhoria nas condições de vida da população do país, a qual pode ser atestada pelas medidas fornecidas por diferentes indicadores sociais (redução da pobreza, expansão do acesso aos serviços de saúde e educação, maior formalização do trabalho, incremento da infraestrutura urbana, entre outros). Contudo, alguns pesquisadores (ARRETCHE, 2015; PIRES, 2019) têm alertado para o fato de que esse avanço nas condições sociais propiciado pela implementação das políticas públicas não atingiu todos os segmentos populacionais da mesma forma, deixando alguns grupos e territórios alijados desse processo. De acordo com Pires (2019), as análises sobre "o efeito social da implementação" possibilitam compreender os múltiplos fatores que podem influenciar nos resultados obtidos pelas políticas públicas, os quais muitas vezes se distanciam dos objetivos previstos no seu planejamento, podendo inclusive vir a reforçar ou reproduzir situações de desigualdade e segregação social e espacial. Nesse sentido, para além da avaliação referente ao cumprimento das metas e objetivos previstos no planejamento das políticas públicas, dos recursos financeiros investidos e do número de beneficiários atendidos, é preciso atentar para a forma como essa é avaliada por aqueles que a vivenciam no seu cotidiano, evidenciando as mudanças que ocorreram nas suas vidas a partir da intervenção da política pública, tanto as consideradas positivas quanto aquelas avaliadas como negativas. Conforme apontado por Rolnick et al. (2015), a distribuição desigual da população no espaço urbano provocada por meio de uma política habitacional, mesmo que esta tenha como objetivo reduzir o déficit de moradia para famílias de baixa renda, pode criar ou reforçar processos de segregação urbana, conforme já foi demonstrado em diversos estudos sobre os efeitos do PMCMV nas metrópoles brasileiras.

A conformação dos diversos territórios também deve ser levada em consideração nas pesquisas que buscam avaliar os efeitos subjetivos das políticas públicas, pois o território, considerado enquanto um espaço socialmente construído, formado por instituições e redes sociais, irá influenciar na forma como os indivíduos se relacionam com a política e seus agentes implementadores. Nesse sentido, as avaliações subjetivas não podem ser pensadas como tendo um caráter eminentemente individual, embora se baseiem nas percepções externadas pelos beneficiários das políticas públicas. A partir da perspectiva da sociologia relacional, Torres, Marques e Bichir (2006, p. 232) afirmam que em geral “[...] as ações do Estado não consideram o papel das redes de relacionamento nas quais estão inseridos os 
indivíduos, seja influenciando a formulação das políticas, seja influenciando o acesso que diferentes grupos terão a elas".

Na mesma direção, Siblot irá dizer que:

\begin{abstract}
[...] as diferentes relações estabelecidas com instituições e agentes públicos têm caráter decisivo na constituição de um "sentido de lugar social" para os indivíduos, pois essas relações têm desdobramentos tanto materiais quanto simbólicos para uma leitura que os usuários fazem sobre sua localização no espaço social (SIBLOT, 2006. APUD PIRES, 2019, p. 19-20).
\end{abstract}

Este estudo compartilha dessas preocupações, na medida em que busca analisar como os moradores de dois conjuntos residenciais, construídos por meio do PMCMV no município de Santa Cruz do Sul/RS, para atender os segmentos populacionais de baixa renda, avaliam os efeitos dessa política habitacional sobre as suas condições de vida. Parte-se, portanto, da premissa de que a localização espacial da moradia, e as redes de sociabilidade que essa localização possibilita, atuam como fatores condicionantes sobre o acesso aos serviços e bens públicos e sobre a forma como os usuários percebem a sua posição social (TORRES, MARQUES, BICHIR, 2006).

$\mathrm{O}$ artigo encontra-se estruturado nas seguintes seções, além desta introdução, da metodologia da pesquisa e das considerações finais. Na primeira seção apresenta-se uma reflexão sobre como vêm sendo desenvolvidas as avaliações de políticas públicas no Brasil e, particularmente, àquelas que têm como foco o PMCMV; em seguida, descreve-se o funcionamento do Programa Minha Casa Minha Vida e a implementação do Programa no município de Santa Cruz do Sul; por fim, são apresentados os resultados sobre o perfil dos moradores dos conjuntos habitacionais e a sua percepção sobre os efeitos provocados pelo seu deslocamento no espaço urbano.

\title{
Metodologia da pesquisa
}

A investigação aqui apresentada analisou a percepção dos usuários sobre os deslocamentos para conjuntos habitacionais, localizados em áreas periféricas da malha urbana. Nesse sentido, procurou-se conhecer os efeitos do PMCMV sobre as distintas dimensões da vida dos moradores desses conjuntos habitacionais, as quais abarcam desde o seu acesso aos serviços de saúde, educação, assistência, segurança pública, transporte, infraestrutura urbana e mercado de trabalho, até as redes de sociabilidade, formas de organização, filiação religiosa e empregabilidade.

Desta forma, a pesquisa partiu da avaliação dos beneficiários da política acerca de como esta atingiu distintas dimensões das suas condições de vida. Segundo Figueiredo e 
Figueiredo (1986, p.116-117), esse tipo de pesquisa visa averiguar a "efetividade subjetiva" da política pública, ou seja, assume a [...] "função de aferir a percepção da população sobre a adequação dos resultados objetivos dos programas aos seus desejos, aspirações e demandas”.

$\mathrm{O}$ artigo analisa os resultados obtidos no survey e nas observações realizadas in loco em dois conjuntos habitacionais: o Residencial Viver Bem e o Residencial Santo Antônio. Em cada um desses conjuntos foi constituída uma amostra representativa do universo de moradores. O questionário aplicado nas residências continha questões referentes ao perfil socioeconômico dos respondentes e de seu grupo familiar, além de questões sobre o acesso aos serviços e equipamentos públicos, às redes de sociabilidade das famílias, os locais e condições de moradia, o acesso ao mercado de trabalho e a participação em associações e cultos religiosos. Todas essas questões eram feitas em relação ao período anterior e após a mudança para os conjuntos, objetivando avaliar as alterações nas condições de vida dos beneficiários da política. Foram aplicados 60 questionários no Residencial Santo Antônio e 130 questionários no Residencial Viver Bem. As respostas dos questionários foram processadas e analisadas com o auxílio do software SPSS.

\section{O debate recente sobre a avaliação de políticas públicas}

A necessidade de se avaliar a efetividade das políticas habitacionais, e as políticas públicas de uma forma mais geral, tem sido defendida tanto por pesquisadores da comunidade científica como por integrantes da gestão pública e de organizações privadas. (RAMOS, SCHABBACH, 2012). Os objetivos pontuais e as metodologias utilizadas para a realização dessas pesquisas avaliativas apresentam variações, embora se perceba uma preocupação comum dos pesquisadores no sentido de produzir informações que possam subsidiar a tomada de decisão por parte dos policymakers quanto à continuidade da política pública, ou à necessidade de sua adequação ou extinção. Nesse sentido, as pesquisas avaliativas caracterizam-se por apresentar uma pretensão de aplicabilidade na gestão pública, embora isto não esteja assegurado e muitas vezes não ocorra de forma efetiva (TREVISAN, BELLEN, 2008). Diversos autores chamaram a atenção para o fato de que a avaliação, assim como ocorreu com a implementação de políticas públicas, tardou a despertar interesse dos acadêmicos e atores estatais no Brasil. Diferentemente do que ocorreu nos processos norteamericano e europeu, nos quais as pesquisas avaliativas passaram a ser realizadas ainda nas décadas de 1960 e 1970, respectivamente, no caso brasileiro essas foram iniciadas somente em meados dos anos de 1990, sob influência da abordagem do New Public Management e do programa de Reforma do Estado (FARIA, 2005; CAPELLA, BRASIL, 2016). 
As mudanças operadas nas formas de atuação dos organismos de cooperação multilateral e ONGs internacionais, no sentido de cobrar a inclusão de metodologias e indicadores de avaliação nos projetos sociais por eles financiados, também tiveram um papel importante na valorização dos processos avaliativos no país. (RAMOS, SCHABBACH, 2012).

Tradicionalmente as avaliações de políticas públicas estiveram direcionadas à aferição da efetividade, eficiência e eficácia dos programas, com base em desenhos de pesquisa experimentais ou quase-experimentais e o uso de metodologias quantitativas. De uma forma geral, esses estudos buscam responder à seguinte pergunta: a política resolveu o problema? Pode-se afirmar que a política funcionou? Infelizmente essas questões não apresentam respostas fáceis, pois há a necessidade de isolar o fator causal da mudança - no caso, a política pública - para poder afirmar que foi a sua implementação que alterou a situação problema e não outros fatores. Em pesquisas sociais, esse isolamento do fator de impacto ou intervenção apresenta muitas dificuldades para ser realizado e, por isso, foram criados delineamentos de pesquisa que buscam contornar esse problema e conferir um maior grau de confiabilidade aos resultados. (BATISTA, DOMINGOS, 2017).

Nos últimos anos, no entanto, tem crescido o número de investigações que se utilizam de procedimentos quanti e qualitativos de forma conjunta ou complementar, permitindo a identificação e a análise de outros fatores que influenciam nos resultados das políticas públicas, sobretudo aqueles não previstos na sua fase de formulação (BATISTA, DOMINGOS, 2017).

Este estudo foi desenvolvido dentro dessa perspectiva, pois acredita-se que o método depende do tipo de problema que se objetiva responder e não simplesmente de uma preferência do pesquisador. O importante a ressaltar é que, independentemente dos procedimentos metodológicos utilizados nas pesquisas avaliativas, todos contribuem para que as decisões envolvendo políticas públicas sejam baseadas em evidências científicas. (BATISTA, DOMINGOS, 2017).

A seguir, apresenta-se as informações referentes ao PMCMV e a sua implementação no município de Santa Cruz do Sul. 


\section{O Programa Minha Casa Minha Vida (PMCMV) em Santa Cruz do Sul}

O Programa Minha Casa Minha Vida foi criado em 2009, durante o segundo Governo Lula, como um pacote de medidas do Governo Federal Brasileiro que visava diminuir o déficit habitacional no país e promover o crescimento econômico por meio do aquecimento da indústria da construção civil (ROLNIK et al., 2015). Os recursos financeiros do Programa foram centralizados no Governo Federal, via Caixa Federal, o que permitiu superar a eventual resistência dos governos locais (municípios). De acordo com os autores, o PMCMV resultou de tratativas estabelecidas entre o Gabinete da Casa Civil da Presidência da República, o Ministério da Fazenda e representantes do setor da construção civil, passando ao largo das instâncias do Ministério das Cidades, o qual era responsável pela formulação das políticas urbanas no país. Salientam, ainda, que o setor imobiliário e as incorporadoras foram altamente beneficiados pelo PMCMV, pois este os salvou da derrocada financeira, provocada pela crise de 2008, e impulsionou o valor de suas ações. Segundo os autores, é indiscutível o papel anticíclico do PMCMV sobre a indústria da construção civil, pois esta apresentou um crescimento de $47,1 \%$ no período de 2003-2013, enquanto o PIB no mesmo período cresceu 45,9\%. Além disso, o setor da construção civil abriu 2,23 milhões de postos de trabalho formais.

Com a previsão inicial de construção de 200 mil moradias voltadas para a faixa de 4 a 10 salários mínimos, o PMCMV teve o investimento aumentado, posteriormente, para cerca de um milhão de unidades habitacionais. Deste contingente, $40 \%$ foram totalmente subsidiadas, abarcando inclusive as classes mais pobres da população com a criação da chamada Faixa 1, voltada ao atendimento das famílias com renda entre 0 e 3 salários mínimos. Na sua última versão, o PMCMV I subdividiu-se da seguinte forma: i) PMCMVEntidades, o qual previa subsídios destinados à produção de moradias por associações e cooperativas; ii) o Programa Nacional Habitação Rural, destinado à construção de moradias para pequenos produtores rurais; iii) o PMCMV Sub 50, voltado aos municípios com menos de 50 mil habitantes; e o iv) o PMCMV - Empresas, o qual possuía o maior número de empreendimentos e apresentava condições diferenciadas conforme as faixas de renda, com subsídios e mecanismos financeiros específicos. É neste último Programa que estava inserida a chamada Faixa 1, aquela destinada a construção de moradias para a população mais pobre (ROLNIK, 2015).

A partir de 2011 foi criado o PMCMV II, como compromisso assumido pela presidenta Dilma, prevendo a construção de mais dois milhões de unidades habitacionais. Nesta fase foram implementadas importantes modificações no programa, como o aumento dos Barbarói, Santa Cruz do Sul, Edição Especial n.54, p.<133-149>, jul./dez. 2019 
custos máximos das unidades e a incorporação de algumas exigências, tais como, a acessibilidade universal para um número mínimo de habitações, o aumento da dimensão dos ambientes e a elevação do padrão mínimo de acabamentos. Além disso, na fase II a faixa de renda de até 3 salários mínimos (Faixa 1) passou a responder por $60 \%$ das contratações. (ROLNIK, 2015).

As políticas públicas habitacionais nos moldes implementados no Brasil, desde a criação do BNH (Banco Nacional de Habitação), em 1964, estiveram intimamente ligadas à especulação imobiliária. Na medida em que os empreendimentos estavam condicionados à lógica de mercado, as habitações de interesse social acabaram por ocupar lugares que não despertavam interesse das classes mais altas e que apresentavam menor valor de mercado (HOFF, 2018). Recuperando o histórico das políticas habitacionais no Brasil a partir da criação do BNH, Marques (2015, p. 226) afirma que durante o regime militar ocorreu uma massificação e elevação das coberturas, mas que estas também estiveram “[...] marcadas por importante seletividade e mesmo desvio de foco, $[\ldots]$ em que elevados subsídios beneficiaram as classes médias em detrimento dos mais pobres." Além disso, o autor (MARQUES, 2015) aponta que o padrão predominante em termos de habitação popular nesse período foi baseado na construção de unidades novas para vendas financiadas em bairros de periferia, reforçando a segregação residencial já existente nas metrópoles.

Em relação ao PMCMV percebe-se que, apesar do êxito em relação à diminuição do déficit habitacional, esse padrão de (re)produção das cidades não chegou a ser alterado. Predomina, ainda, a lógica das incorporadoras e da indústria da construção civil, a qual preserva a dinâmica da segregação urbana nos empreendimentos financiados pelo Programa. $\mathrm{Na}$ visão de Rolnik et al.(2015), a implementação do PMCMV produziu novas áreas periféricas e/ou o adensamento de territórios já ocupados por sub habitações, contribuindo com a manutenção e reforço das situações de exclusão e segregação urbana. 


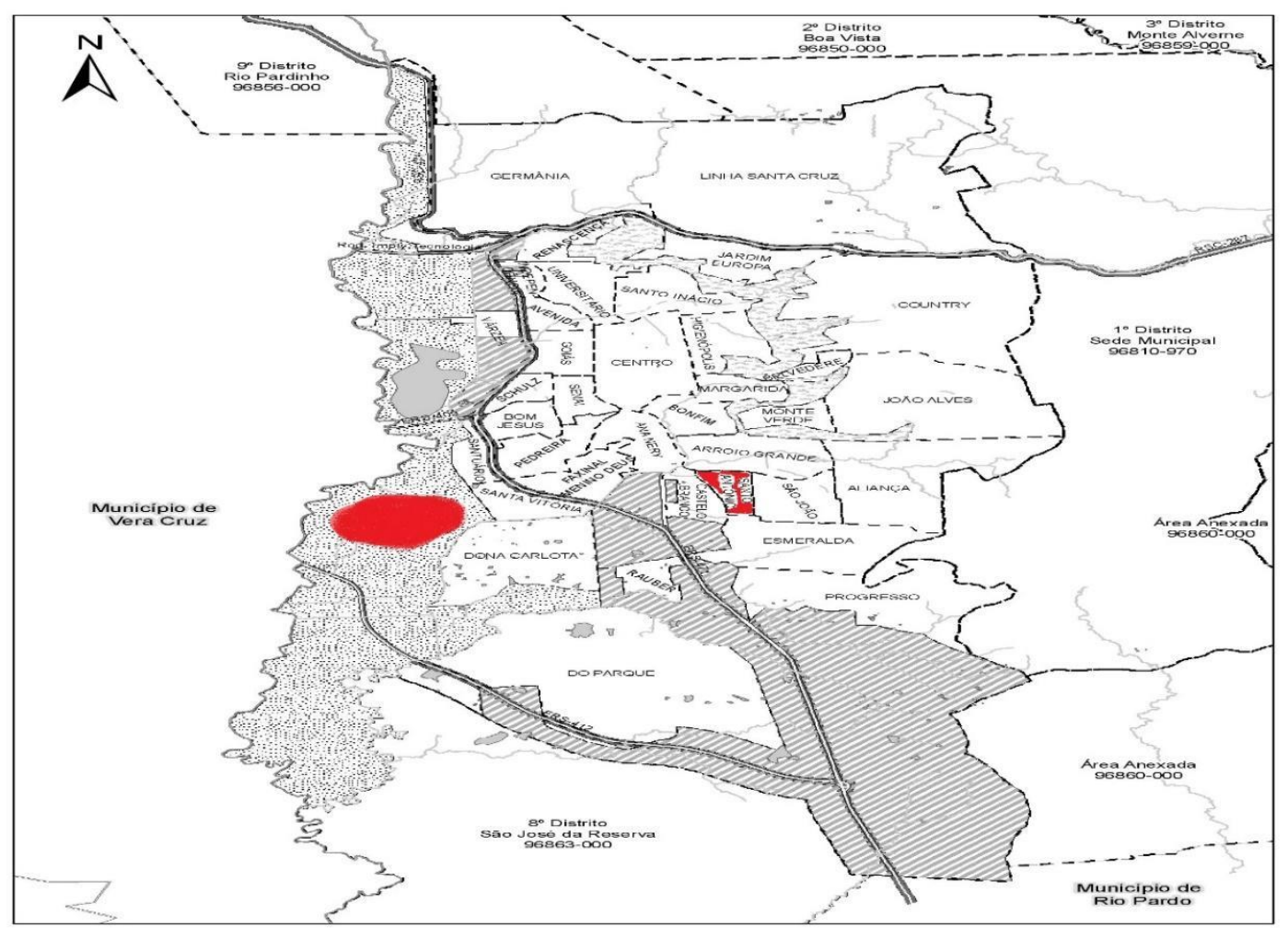

Figura 1- Mapa da localização dos conjuntos residenciais construídos através do programa Minha Casa Minha Vida (PMCMV) em Santa Cruz do Sul. Fonte: Prefeitura Municipal de Santa Cruz do Sul

Como pode ser observado no mapa acima, no município de Santa Cruz do Sul foram construídos dois conjuntos habitacionais a partir de financiamento do PMCMV na periferia sul do município: o Residencial Santo Antônio, localizado no Bairro Progresso e o Residencial Viver Bem, situado no Bairro Dona Carlota.

Os apartamentos do Residencial Santo Antônio foram entregues aos beneficiários em 2012, enquanto que as casas do Residencial Viver Bem foram entregues três anos depois, em 2015. No primeiro residencial foram contempladas 242 famílias com apartamentos distribuídos em 13 prédios de cinco pavimentos. Ali foram beneficiadas famílias em condições de vulnerabilidade social, grande parte residentes, anteriormente, em áreas de risco ou insalubres. 


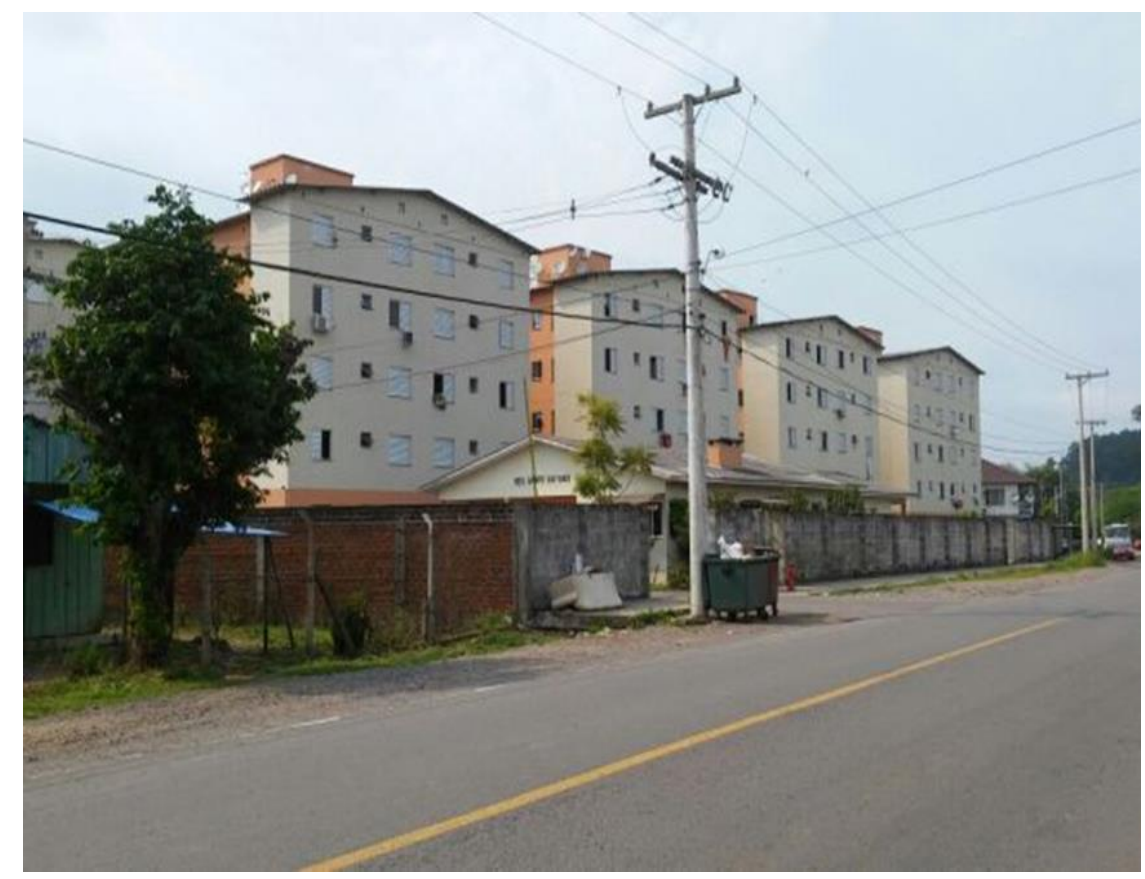

Figura 2: Residencial Santo Antônio. Fonte: Portal Gaz

Embora existam núcleos habitacionais populares espalhados pela zona urbana de Santa Cruz, os empreendimentos habitacionais voltados para as classes mais baixas da população e financiados por programas sociais federais nos últimos dez anos foram construídos em áreas da zona sul (HOFF, 2018).

Assim, a periferia sul vem se reafirmando como o lugar dos pobres na cidade e, apesar de contar com bens e serviços públicos, estes se apresentam com qualidade e quantidade aquém do necessário para abrigar a população que lá tem se instalado, especialmente em grandes conjuntos habitacionais como o Viver Bem, que recebeu mais de 900 famílias deslocadas de vários bairros da cidade. 


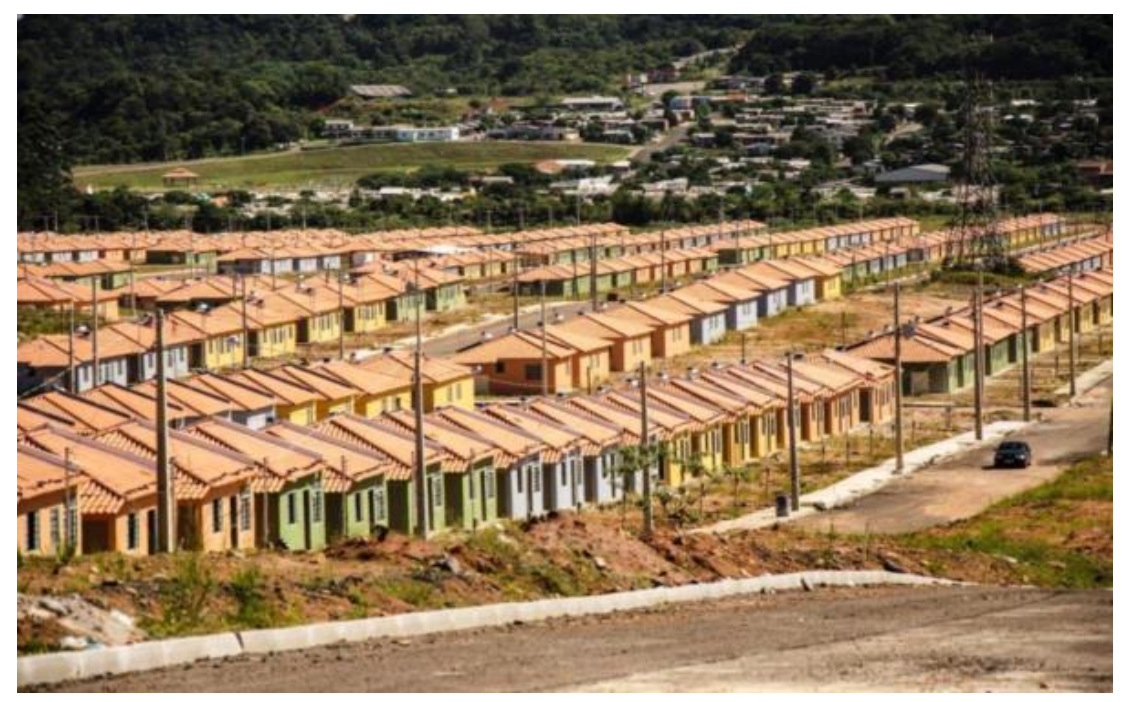

Figura 3: Residencial Viver Bem. Fonte: Portal Gaz

No Residencial Viver Bem foram contempladas 908 famílias, a partir de critérios envolvendo a renda (até três salários mínimos), famílias chefiadas por mulheres, familiares com algum tipo de deficiência, idosos, dependentes menores de 18 anos e trabalhadores da reciclagem.

Tanto no Residencial Santo Antônio como no Viver Bem, há um número expressivo de mulheres, correspondendo a mais da metade da população dos residenciais, $59 \%$ e $56 \%$ respectivamente. Quanto à escolaridade, percebe-se que em ambos os conjuntos habitacionais há um nível de escolaridade muito baixo. No Viver Bem, 61,8\% das pessoas possuem Ensino Fundamental incompleto, enquanto esse número corresponde a 58,5\% no Santo Antônio. No Viver Bem, apenas 1,4\% possuem Ensino Superior Completo e no Res. Santo Antônio não há graduados entre a amostra estudada.

Entre aqueles que responderam aos questionários, observou-se que há uma taxa elevada de desempregados nos dois locais, perfazendo o total de $41 \%$ no Santo Antônio, e $51 \%$ no Viver Bem. Dentre os que afirmaram estar trabalhando no Res. Santo Antônio, destacam-se as seguintes ocupações: 16,2\% são profissionais autônomos ou trabalhadores do comércio, vindo em seguida trabalhadores domésticos $(14,9 \%)$, da indústria $(13,5 \%)$ e safristas $^{2}(12,2 \%)$. Já no Res. Viver Bem as profissões mais destacadas são: safristas $(21,7 \%)$, trabalhadores do comércio $(15,9 \%)$, trabalhadores da indústria e profissionais autônomos (10,9\% ambos) e, operários da construção civil (8\%). Em ambos os conjuntos

\footnotetext{
${ }^{2}$ Denomina-se safristas aqueles trabalhadores que se mantém empregados formalmente somente alguns meses do ano, a produção na indústria fumageira tem dois períodos entre janeiro e junho/julho, em que o tabaco produzido é processado, as máquinas trabalham a "todo vapor", por isso são contratados muitos trabalhadores temporários, chamados na região de Santa Cruz do Sul de "safristas". (CADONÀ, FREITAS, 2016, p.248).
}

Barbarói, Santa Cruz do Sul, Edição Especial n.54, p.<133-149>, jul./dez. 2019 
habitacionais percebe-se que a maior parte das ocupações requerem baixa qualificação e possuem alta volatilidade, o que indica distintas formas de precarização do trabalho. Salientase que o maior percentual é de profissionais autônomos, do comércio e safristas que trabalham nas empresas fumageiras do município e que tem caráter sazonal (safras, festas, bicos).

Desta forma percebe-se que o perfil dos moradores dos residenciais contemplados no PMCMV em Santa Cruz do Sul é marcado pela vulnerabilidade das classes mais pobres e seu assentamento na região periférica (zona sul do município), restringindo as possibilidades de acesso aos serviços públicos e às formas de rompimento com a situação de pobreza.

No entanto, para além de constituir o perfil dos moradores dos conjuntos habitacionais do município de Santa Cruz do Sul, cabe avaliar os efeitos do PMCMV sobre as várias dimensões de vida dos seus beneficiários, possibilitando conhecer a percepção dos moradores em relação às mudanças provocadas pelo seu deslocamento no espaço urbano.

\section{A efetividade subjetiva do PMCMV: a percepção dos beneficiários}

Nesta seção apresenta-se os resultados da avaliação dos beneficiários nos dois conjuntos habitacionais sobre a situação em que se encontravam antes da implementação do PMCMV e após terem sido beneficiados com as moradias em diferentes dimensões das suas vidas.

Entre os aspectos analisados, destaca-se a avaliação positiva dos beneficiários sobre as suas condições de moradia após terem acessado o Programa. Esta avaliação pode ser explicada pelo fato de grande parte dos beneficiários nos dois conjuntos habitacionais não possuírem casa própria anteriormente, 68\% no Res. Santo Antônio e 73,8\%, no Res. Viver Bem. Salienta-se que $92 \%$ dos moradores de ambos os residenciais viviam em casas alugadas ou emprestadas. Livrar-se do pagamento de aluguel é uma das razões principais referidas pelos moradores quando manifestam a sua satisfação com o fato de serem proprietários. Vários entrevistados disseram que, apesar dos problemas existentes na construção dos imóveis, adquirir a casa própria ou "ter o cantinho da gente" foi a melhor coisa que lhes aconteceu.

No residencial Santo Antônio 68,4\% dos moradores salientam que a sua condição de moradia melhorou ou melhorou muito após a mudança; já no residencial Viver Bem são $74,2 \%$ os que afirmam a melhora nas condições de moradia. Esses resultados evidenciam o quanto, no caso brasileiro, a solução para os problemas de moradia é percebida pela população como estando assentada no acesso à propriedade privada de uma unidade residencial. 
No entanto, apesar dessa avaliação positiva associada a condição da moradia atual, muitos beneficiários expressaram o seu descontentamento em relação à qualidade da construção e a escolha dos locais dos residenciais, sobretudo no caso do Res. Viver Bem, o qual está localizado em um bairro mais isolado e com problemas de escoamento de água. 47\% dos moradores desse residencial afirmaram que as necessidades dos beneficiários não foram levadas em consideração quando foram construídas as casas. E também durante as entrevistas foram apontados muitos problemas com relação a construção das casas (material de baixa qualidade, falta de acessibilidade para residências com pessoas com deficiência, falta de acompanhamento da construtora após a obra, infraestrutura do bairro). Segundo relata um morador: "A casa apresenta goteiras, chove para dentro, tem mofo, rachaduras, sujeira na caixa d'água, esgoto... Há um jogo de empurra-empurra entre Prefeitura e Caixa" (Morador Viver Bem).

Com relação ao acesso aos serviços de saúde encontrou-se diferenças bem significativas entre a avaliação dos moradores nos conjuntos estudados. Enquanto a maioria $(51,8 \%)$ dos moradores do Santo Antônio afirmam que melhorou o acesso aos serviços de saúde (postos de saúde, ESF) em relação ao período anterior a mudança, a maioria (58\%) dos moradores do Viver Bem apontam que piorou, ou piorou muito esse acesso. No caso do Res. Santo Antônio, são disponibilizados dois equipamentos de saúde em locais próximos (ESF e um hospital/dia), diferentemente do Res. Viver Bem, em que os moradores precisam acessar esses serviços em outros bairros do município.

Apesar das promessas de instalação de equipamentos e serviços públicos pela prefeitura municipal para os moradores deste residencial, o poder público municipal não construiu uma estrutura própria para o Residencial. A aposta feita pela gestão a época foi que os próprios moradores construíssem soluções e que as famílias mantivessem seus vínculos com os serviços públicos existentes nos bairros em que residiam anteriormente.

Considerando a distância em relação aos bairros de origem e as condições de renda e vulnerabilidade da população, pode-se afirmar que a relação das famílias do Residencial com os serviços de saúde se fragilizou a partir do deslocamento para o novo endereço. (CADONÁ, TIRELLI, AREOSA, 2017). 


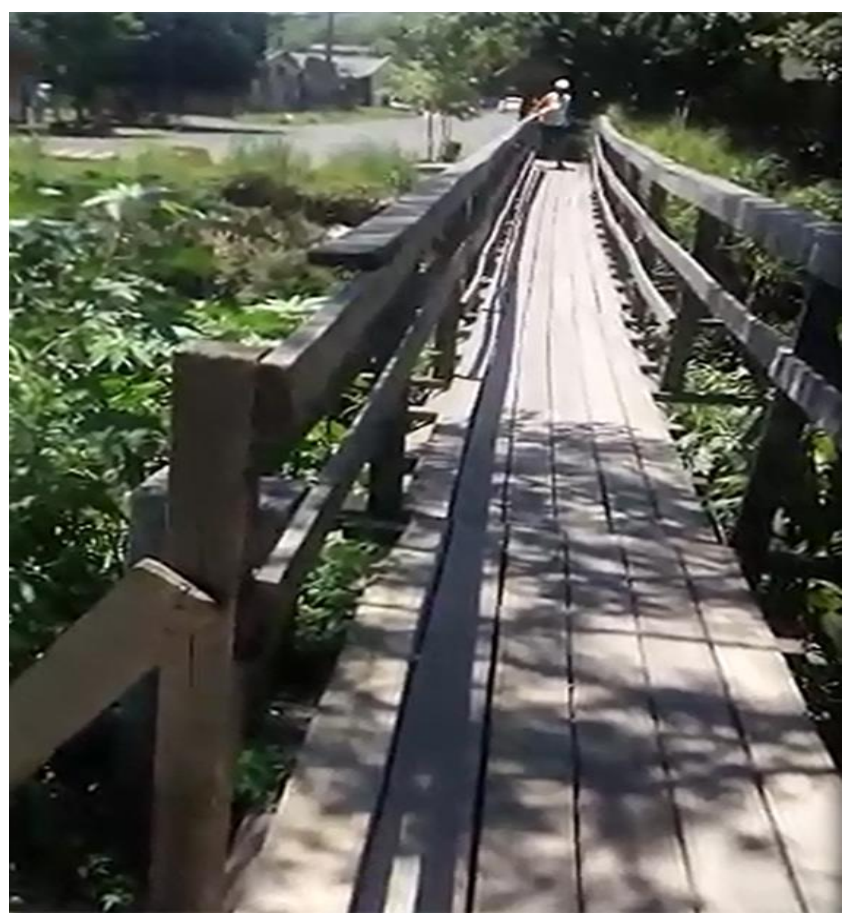

Figura 4: Ponte que liga o residencial Viver Bem ao bairro Santa Vitória. Fonte: Portal Gaz

Já em relação à segurança pública, os moradores do Santo Antônio possuem uma avaliação muito negativa, afirmando que piorou ou piorou muito (59\%), enquanto que os moradores do Viver Bem acreditam que as condições de segurança pública estão iguais (48\%) ou melhoraram (20,5\%). Atribui-se essa diferença nas percepções dos moradores às tipologias de construção utilizadas em cada conjunto habitacional. No residencial Sto. Antônio, o modelo utilizado foi o de construção de prédios de 5 pavimentos e de condomínio murado. Ao passo que no Viver Bem, foram construídas casas em espaço aberto. No primeiro observa-se uma escalada de violência dentro dos muros do condomínio, dominado por facções ligadas ao tráfico de drogas, e ausência do Poder Público.

Os resultados relativos a infraestrutura urbana (calçamento, iluminação, coleta de lixo, saneamento) não diferem muito entre os entrevistados do Res. Santo Antônio (45,9\%) e do Res. Viver Bem (39,4\%), pois em ambos os moradores dizem que as condições de infraestrutura estão iguais às que possuíam anteriormente, pois grande parte desses já residiam na região da periferia sul da cidade em condições semelhantes; porém, 29,5\% e 32,3\% (respectivamente), avaliam que a infraestrutura melhorou após a mudança. Em geral, esses moradores são os mais vulneráveis, que foram removidos de locais de risco.

Em relação a rede de ajuda mútua e a organização dos moradores, os beneficiários do Santo Antônio afirmaram em sua maioria (50,9\%) que a ajuda de parentes e vizinhos piorou após a mudança e que a organização dos moradores piorou ou piorou muito $(53,4 \%)$. No 
Viver Bem, os entrevistados responderam, em sua maioria, que a ajuda está igual $(47,5 \%)$ ou melhorou $(22,5 \%)$, da mesma forma que a organização dos moradores, a qual, na sua avaliação, está igual $(53,2 \%)$ ou melhorou (22\%) em relação aos locais onde residiam antes do deslocamento.

Desta forma, percebe-se que os efeitos sobre a rede de sociabilidade não se deram da mesma forma nos dois condomínios, assim como a percepção sobre a segurança pública. Entre os moradores do condomínio vertical e murado, existe uma sensação de maior insegurança que é evidenciada nas suas falas quando afirmam terem medo de deixar as crianças brincarem na praça do condomínio ou circularem sozinhas pelo residencial. Também observou-se neste residencial uma significativa parcela de apartamentos que foram abandonados ou revendidos, não sendo nestes casos os beneficiários os moradores encontrados pelos entrevistadores.

Enquanto isso, os moradores do condomínio horizontal acreditam, em sua maioria, que sua segurança ficou igual ou melhorou após a mudança. Estes continuam residindo em casas como antes e agora casas de alvenaria, além de não terem queixas de falta de policiamento no bairro.

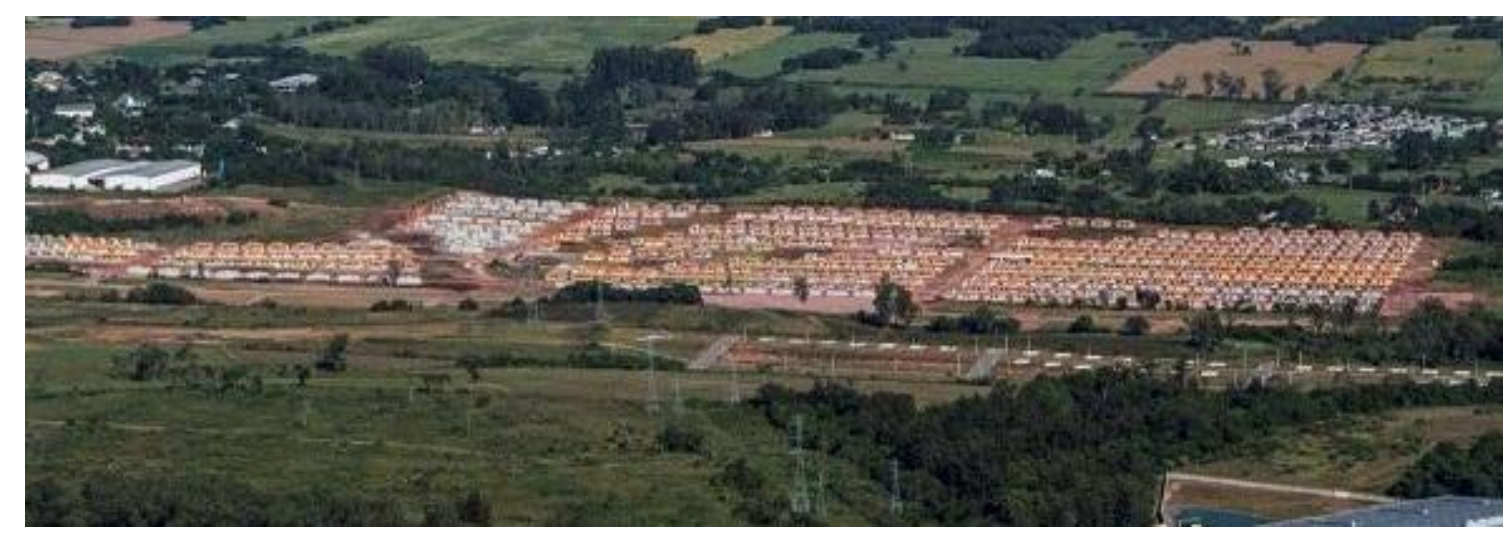

Figura 5: Foto panorâmica do Res. Viver Bem. Fonte: Portal Gaz

No entanto, percebe-se um descontentamento dos moradores com relação a insuficiência de investimentos da gestão pública municipal em obras de mobilidade urbana, lazer e serviços públicos de educação e saúde. Segundo a fala de um morador entrevistado: “[Aqui] falta tudo, ponte, colégio, creche, posto de saúde, local de lazer” (Morador Viver Bem). 


\title{
Considerações finais
}

Analisando os resultados da pesquisa percebe-se que o perfil dos moradores dos residenciais contemplados no PMCMV em Santa Cruz do Sul é marcado pela vulnerabilidade das classes mais pobres e seu assentamento foi feito na região periférica da cidade, sendo muito semelhante nos dois conjuntos as características como escolaridade, sexo e condições de trabalho e renda.

No entanto existem diferenças nas suas percepções com relação à violência, às redes de ajuda mútua e o acesso aos serviços públicos. Estes achados reforçam a importância de se fazerem na academia estudos empíricos para avaliar a implementação das políticas públicas e a sua efetividade subjetiva, principalmente, estudos que considerem a influência dos fatores de ordem supraindividual.

Os moradores do Residencial Santo Antônio apontam a violência como um dos seus principais problemas, enquanto que os moradores do residencial Viver Bem trazem as dificuldades de acesso aos serviços de saúde, educação e transporte público como sendo os principais problemas da moradia atual. O fato deste último residencial situar-se em um local bem mais isolado da malha urbana, ajuda a compreensão das percepções dos seus moradores.

\section{THE MINHA CASA MINHA VIDA PROGRAM IMPLEMENTATION IN SANTA CRUZ DO SUL: THE BENEFICIARIES PERCEPTION}

\begin{abstract}
The article discusses the results of an evaluative research conducted with residents of two housing estates built in Santa Cruz do Sul / RS, through the Minha Casa Minha Vida Program (PMCMV). By conducting a survey and direct observations in the residences, we sought to analyze how the beneficiaries of the Program perceive the effects of its implementation, which resulted in their displacement in the urban space and changes in their sociability networks, housing conditions and access to public services and facilities. Based on these data, it was possible to apprehend the "subjective effectiveness" of the Program, which differs from the evaluations that seek to assess whether the goals and objectives foreseen in the policy formulation phase were achieved. The study pointed out that the implementation of the PMCMV led to the acquisition of "home ownership", but brought several side effects to its beneficiaries, depending on the location of the housing development in the urban space and the typology used in the construction of residential units (houses or buildings) walled or open sets) and their forms of management. These unexpected effects include the increase in violence linked to drug trafficking, difficulties in establishing rules and new ties in social life, the distance from public services and the indebtedness, abandonment and occupation of homes.
\end{abstract}

Keywords: Minha Casa Minha Vida Program, public policy, implementation. 


\section{REFERÊNCIAS}

ARRETCHE, Marta. Trazendo o conceito de cidadania de volta: a propósito das desigualdades territoriais. In: ARRETCHE, Marta (org.). Trajetórias das Desigualdades: como o Brasil mudou nos últimos cinquenta anos. São Paulo: UNESP/CEM, 2015. p. 193222.

BATISTA, Mariana; DOMINGOS, Amanda. Mais que boas intenções: técnicas quantitativas e qualitativas na avaliação de impacto de políticas públicas. RBCS, v. 32 n. 94, jun. 2017.

BRASIL, Felipe G.; CAPELLA, Ana Cláudia. Os Estudos das Políticas Públicas no Brasil: passado, presente e caminhos futuros da pesquisa sobre análise de políticas. Revista Política Hoje, v. 25, n. 1, p. 71-90, 2016.

CADONÁ, Marco A.; FREITAS, Valter. Trabalho e precarização dos empregos: trabalhadores temporários na indústria fumageira de Santa Cruz do Sul (RS) Revista Baru, Goiânia, v. 2, n. 2, p. 247-263, jul./dez. 2016.

CADONÁ, Marco; TIRELLI, Cláudia; AREOSA, Silvia V.C. Políticas habitacionais, segregação residencial e desigualdade no acesso às políticas públicas: uma análise a partir do acesso a serviços públicos de saúde. Redes - Santa Cruz do Sul: Universidade de Santa Cruz do Sul, v. 22, n. 1, p. 326-345, jan./abri. 2017.

FARIA, Carlos Aurélio Pimenta de. A política da avaliação de políticas públicas. Revista Brasileira de Ciências Sociais, v. 20, n. 59, 97-110, out. 2005.

FIGUEIREDO, Marcus; FIGUEREIDO, Angelina. Avaliação política e avaliação de políticas: um quadro de referência teórica. Análise e Conjuntura, Belo Horizonte, v. 1, n. 3 , p. 107-127, 1986.

HOFF, Tuize Silva Rovere. A cidade e a mulher: segregação urbana feminina em Santa Cruz do Sul/RS. 2018. 146 f. Dissertação (Programa de Pós-Graduação em Desenvolvimento Regional - Mestrado e Doutorado) - Universidade de Santa Cruz do Sul, Santa Cruz do Sul, 2018.

MARQUES, Eduardo et al. Os desafios da metrópole: desigualdades sociais, Estado e segregação na metrópole. In: LAVALLE, A. G. O horizonte da política: questões emergentes e agendas de pesquisa. São Paulo: UNESP/CEBRAP/CEM, 2012. p. 63-96.

MARQUES, Eduardo. Condições habitacionais e urbanas no Brasil. In: ARRETCHE, Martha (org.). Trajetórias das Desigualdades: como o Brasil mudou nos últimos cinquenta anos. São Paulo: UNESP/CEM, 2015. p. 223-247.

PIRES, Roberto Rocha. Introdução. In: PIRES, Roberto Rocha (org.). Implementando desigualdades: reprodução de desigualdades na implementação de políticas públicas. Rio de Janeiro: Ipea, 2019. p. 13-50.

RAMOS, Marília. P.; SCHABBACH, Letícia. O estado da arte da avaliação de políticas públicas: conceituação e exemplos de avaliação no Brasil. Rev. Adm. Pública, Rio de Janeiro, v.46, n.5, p.1271-294, set./out. 2012. 
ROLNIK, Raquel. Guerra dos Lugares: a colonização da terra e da moradia na era das finanças. São Paulo: Boitempo, 2015.

ROLNIK, Raquel et al. O Programa Minha Casa Minha Vida nas regiões metropolitanas de São Paulo e Campinas: aspectos socioespaciais e segregação. Cad. Metrop. São Paulo, v. 17, n. 33, p. 127-154, mai. 2015.

TORRES, Haroldo da Gama; MARQUES, Eduardo César; BICHIR, Renato Mirandola. Políticas públicas, pobreza urbana e segregação residencial. In: CUNHA, José Marcos Pinto da. Novas metrópoles paulistas: população, vulnerabilidade e segregação. Campinas: Nepo/Unicamp, p. 231-254, 2006.

TREVISAN, Andrei P.; VAN BELLEN, Hans M. Avaliação de políticas: Uma revisão teórica de um campo em construção. RAP - Rio de Janeiro v.42, n.3, p. 529-50, mai./jun. 2008.

\section{Sobre as autoras:}

Claudia Tirelli é Doutora em Sociologia. UNISC, Universidade de Santa Cruz do Sul. Endereço: Av. Independência, 2293, Bairro Universitário, Santa Cruz do Sul, RS, Brasil. Endereço eletrônico: ctirelli@unisc.br

Sílvia Virgínia Coutinho é Doutora em Serviço Social. UNISC, Universidade de Santa Cruz do Sul. Endereço: Av. Independência, 2293, Bairro Universitário, Santa Cruz do Sul, RS, Brasil. Endereço eletrônico: sareosa @ unisc.br 